\title{
Nanostructured coatings for super hydrophobic textiles
}

\author{
M JOSHI*, A BHATTACHARYYA, N AGARWAL and S PARMAR \\ Department of Textile Technology, Indian Institute of Technology, Delhi 110 076, India
}

MS received 28 March 2012

\begin{abstract}
The promising aspects of nanocomposite coatings to mimic the nano roughened self cleaning surface of lotus leaf is explored in this paper. A detailed study on nanosilica and clay based nanocomposite coatings using dip coating and layer by layer self assembly $(\mathrm{L}-\mathrm{b}-\mathrm{L})$ is being described where lotus leaf effect has been mimicked on the cotton fabric surface using these particles as they develop nanosized surface roughness which helps to produce a super-hydrophobic surface. Nanosilica performs better in creating nano roughness on cotton fabric wherein the contact angle is $>150^{\circ}$. The water contact angle of $2 \mathrm{wt} \%$ fluoro emulsion (Nuva HPU) treated cotton fabric increases from $115^{\circ}$ to $155^{\circ}$ when the fabric is pretreated with $0.5 \mathrm{wt} \%$ nanosilica emulsion. The water repellency rating of fabric treated with 0.16 wt \% nanosilica along with 2 wt \% Nuva HPU is comparable to that of 4 wt\% Nuva HPU treated cotton fabric. On the other hand, 40 bilayers of nanosilica need to be applied on cotton fabric surface through L-b-L technique to create uniform nano roughening and gives a water repellency rating of 4 . The air permeability of $\mathrm{L}-\mathrm{b}-\mathrm{L}$ nanocoated cotton fabric is not adversely affected by the super-hydrophobic nanostructured coating.
\end{abstract}

Keywords. Super hydrophobic; nanocomposite coating; layer-by-layer; nanoclay; nanosilica.

\section{Introduction}

Nanostructured coating on textiles is a novel way to impart various functional properties such as gas barrier, antibacterial, abrasion resistance, UV resistance, flame retardant and super hydrophobic. Nanomaterials such as layered silicate clays, carbon nanofibre/nanotubes, nanosilica, nano $\mathrm{TiO}_{2}$ have been incorporated in the base polymeric coating to enhance the performance of coated textiles to achieve these properties on fabrics (Joshi and Bhattacharyya 2011).

Barthlott and Ehler (1977) discovered in 1990 that the self-cleaning property of the lotus leaf is because of the high density of minute surface protrusions. A close look at the surface of lotus leaf reveals its structural uniqueness which is a combination of nano and micro roughened surface along with some surface tension lowering agent, wax. This phenomenon is known as "lotus leaf effect". While the nanoroughening does not allow any water molecule to absorb on the surface, water drops sit on the nano protrusions and roll from the leaf surface, removing dust as it moves. Superhydrophobic surfaces mimicking such nano protrusions have drawn researcher's attention (Zhang et al 2008) to mimic this on fabric surface to develop oil water repellent garments and for specific applications like sails or shelter fabrics. Superhydrophobic nano-roughened surfaces can be prepared by controlling surface topography by various processing methods, such as sol-gel method, organic/inorganic hybrid method, CVD method, electrochemical method, embossing method, plasma method, phase separation method, template, etc. Another process for preparation of super-hydrophobic

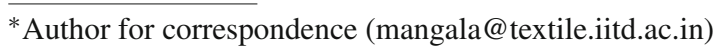

silica based surfaces on glass is by adding polypropylene gly$\mathrm{col}(\mathrm{PPG})$ polymer into the silica precursor and subsequently, removing the PPG at $500^{\circ} \mathrm{C}$, leaving a nano-roughened surface (Chang et al 2007). But this process cannot be adopted on fabric surface because of the high temperature used.

Super-hydrophobic cotton surfaces have been prepared by sol-gel method based on silica nanoparticles and perfluorooctylated quaternary ammonium silane (PFSC) coupling agent. In this combined technique, nano-roughening and surface energy lowering are introduced with the help of two components which mimic the lotus leaf (Yu et al 2007). In another study, nanocomposite coating of silica nanoparticle in perfluoroacrylate based water repellent agent produces super-hydrophobic cotton fabrics. The combined treatment of nano-roughening and surface tension lowering agent reduces the amount of noneco-friendly fluoro compound to $0 \cdot 1 \mathrm{wt} \%$ (Bae et al 2009). The nano-roughening imparted by silica nanoparticles are not durable as silica cannot bind to cotton surface. However, silica nanoparticles can be suitably functionalized or can be used as a component of nanocomposite coating to adhere with cotton surface. Amino functionalized silica nanoparticles applied on epoxy functionalized cotton fabric shows excellent super-hydrophobicity $\left(\sim 170^{\circ}\right)$. The functionalization of silica and cotton surface helps to create strong bond between the fibre and particles. Thus produced nano roughening on fibre surface is very robust and durable (Xue et al 2009). Besides the water repellent lotus effect, nanosilica can also be utilized to develop wrinkle free silk (Wong et al 2006), to reduce the friction and wear of nylon-6 (Garci et al 2004) and polyurethane coating (Song et al 2008) and to increase the flame resistance property of textiles (Kashiwagi et al 2003). 
In the present study, nanosilica and nanoclay particles were used to develop nano roughness on fabric with a goal to create super hydrophobic cotton. Dip coating as well as layer-by-layer self assembly (L-b-L) technique are being investigated for their suitability in creating such nano roughened surface on textiles. L-b-L self assembly method is most promising to deposit nanoparticles with proper alignment so that the nano-protrusions are uniformly developed on fabric surface. L-b-L self assembly approach has been used to develop antibacterial nanocoating of chitosan on cotton fabric (Joshi et al 2011).

This paper reveals that with the help of nanoparticles such as nanosilica and nanoclay along with a surface tension lowering agent, the super hydrophobic property of lotus leaf can be achieved on cotton fabric. Moreover, the process can minimize the amount of fluorocarbon based resin finishes on the fabric and thus provide an environment friendly option for creating self cleaning surfaces.

\section{Experimental}

\subsection{Material}

Nanosilica and nanoclay (kaolinite) particles were used to create nano-roughening on a fabric. A nanosilica colloidal dispersion Aerodisp W7520N was procured from M/s Degussa Chemicals Ltd. It is a water based dispersion of 20 wt\% aerosol fumed silica with $\mathrm{NaOH}$ stabilizing agent ( $\mathrm{pH}$ around 10). Kaolin nanoclay having an average platelet size of $102 \mathrm{~nm}$ was supplied by English Indian Clays Ltd. For layer-by-layer (L-b-L) application, Sandene 2000, an aliphatic polyamine and cationizing agent $(\mathrm{M} / \mathrm{s}$ Clariant India Ltd., India) was used to activate the cotton surface. Poly (allyl amine hydrochloride) (PAH), a cationic polyelectrolyte from Sigma Aldrich and poly (sodium $p$ styrene sulfonate) (PSS), an anionic polyelectrolyte from M/s Acros Organic were used to produce the body layer during $\mathrm{L}-\mathrm{b}-\mathrm{L}$ process. Nuva HPU, a fluorocarbon based finish (perfluoroalkyl acrylic copolymerisate emulsion) from Clariant India Ltd. was used as surface energy lowering agent while nonfluorocarbon based surface energy lowering agents like Cerol emulsion (a dispersion of melamine and paraffin wax) was procured from Clariant India Ltd. Bleached, ready for dyeing pure cotton fabric of $120 \mathrm{~g} \mathrm{~m}^{-2}$, plain weave was used as a substrate. Arkofix NDF ( $N, N^{\prime}$-dimethylol-4, 5dihydroxyethylene-urea based reagent) from Clariant India Ltd. was used as a cross-linking agent which has a very low free formaldehyde content after curing.

\subsection{Method}

Two methods were used to develop nano-roughened super hydrophobic surface. Dip coating was used to coat nanoclay and nanosilica on the fabric while L-b-L method was used to develop nanosilica coating on cotton surface.
In the first method, nanoclay was dispersed in deionized water with $1 \mathrm{~h}$ ultrasonic treatment at $37 \mathrm{kHz}$. The nanosilica and nanoclay dispersions were applied to the cotton fabric by two-step process where nanoparticles were coated, followed by surface energy lowering agent. As the nanoparticle dispersions were stable at alkaline $\mathrm{pH}(\sim 10)$ and the surface tension lowering agents were applied in acidic $\mathrm{pH}$ (3-4), it is not recommended to go for one bath process. The typical recipe is as follows: nanoparticle $-0 \cdot 1-1 \%(\mathrm{w} / \mathrm{v})$; arkofix NDF (cross-linking agent) - 3\% (w/v); nuva HPU $2 \%(\mathrm{w} / \mathrm{v})$ and cerol emulsion $-2 \%(\mathrm{w} / \mathrm{v})$.

All the ingredients were taken as weight percentage on volume of deionized water. Nanoparticles were first dispersed into water and ultrasonic treatment for $1 \mathrm{~h}$. Then the dispersion was padded with cross linking agent Arcofix on the cotton fabric in 2-dip, 2-nip process at $75 \%$ padding expression and dried at $80^{\circ} \mathrm{C}$ for $2 \mathrm{~min}$. The fabric was then padded using a mixture of all other ingredients added for surface tension lowering and cross-linking, dried and cured at $150^{\circ} \mathrm{C}$ for $3 \mathrm{~min}$. For combined application of two nanoparticles, kaolin was first applied followed by Arkofix, nanosilica and other ingredients.

In the second method, nanosilica was coated on activated cotton surface by L-b-L deposition technique. The fabric surface was first cationically activated by treating with $3.5 \mathrm{wt} \%$ Sandene 2000 solution (Material Liquor ratio, 1:20) for $20 \mathrm{~min}$ at $60^{\circ} \mathrm{C}$ and was dried at room temperature. Then the adhesion layer on fabric surface was created by dipping for $30 \mathrm{~s}$ alternately in $0 \cdot 0 \cdot 1 \mathrm{M}$ of PSS ( $\mathrm{pH} \mathrm{6)}$ and $0 \cdot 01 \mathrm{M}$ of PAH ( $\mathrm{pH} 4$ ) aqueous solution. After each dipping, the excess amount was removed using ultrasonic treatment. Three bilayers of such polyelectrolyte pairs were deposited to create the adhesion promoting multilayer. Then for the body layers, PSS was replaced by $0.5 \mathrm{wt} \%$ solution of negatively charged nanosilica Aerodisp W7520N. After required numbers of bilayers were deposited on cotton fabric, it was dried at room temperature and padded with 2 wt $\%$ Nuva HPU and cured at $160^{\circ} \mathrm{C}$ for $2 \mathrm{~min}$.

\subsection{Characterization}

The AFM images were taken in tapping mode of Multimode Scanning Probe Microscope from Vecco Instruments Inc. USA, using ACT; Si, $n$-type probe (resistance 0.001$0.025 \mathrm{ohm} / \mathrm{cm}, L=125 \mu \mathrm{m}, W=45 \mu \mathrm{m}, T=$ $4 \mu \mathrm{m}$, tip radius $<10 \mathrm{~nm}, H=12-16 \mu \mathrm{m}, k=25-$ $75 \mathrm{~N} / \mathrm{m}$, frequency, $200-400 \mathrm{kHz}$; set at $281 \mathrm{kHz}$ ) on the silica and clay deposited surface of thin glass plate (deposition of $1 \mathrm{wt} \%$ nanoparticles in each case by two-step method). The same process was repeated on cotton surface and SEM images were taken on Carl Zeiss EVO50. Photographs of $10 \mu \mathrm{L}$ water drops were analysed and contact angles were measured through DSA 100 Goniometer from Kruss Inc., Germany. Bundesmann rain shower test was carried out to check the water repellent effect of different fabrics. For this, water collected in $2 \mathrm{~min}$ in 
sample holders mounted at $45^{\circ}$ without and with samples were noted down when the shower of rain fell from top. Difference between the collected water of blank and with sample will give an idea of hydrophobic effect. Water repellency test was also carried out by AATCC 193-2005 test method where rating of 1 to 8 is given on the basis of water repellency and rating 8 is for the highest repellency. The air permeability of the layer-by-layer nanosilica treated samples was tested with BS ISO 5636 test method at $100 \mathrm{~Pa}$ by FX3300 Labotester III from Textest Instruments, Switzerland.

\section{Results and discussion}

\subsection{Atomic force microscope images}

The AFM images reveal that the lotus leaf effect can be mimicked on cotton surface using nanosilica or nanoclay (kaolinite) particles. The nanoparticle deposited under same condition on cotton fabric shows excellent hydrophobic property as shown in figure 1, where the corresponding water drop images are shown below the AFM images. However, nanosilica performs best due to its smaller dimension and uniformity in creating the roughened surface (figure 1a). The kaolin nanoclay and combination of nanosilica and kaolin nanoparticles show less contact angle than the nanosilica deposited cotton fabric. This is due to the plate-like structure of nanoclay (figure 1b) which somewhat hinders the rolling of water from fabric surface. Also the nanosilica accumulates in between the clay platelets and creates uneven roughness on the surface as observed in figure 1c.

\subsection{Scanning electron microscope images}

The SEM images of the cotton fibre and nanosilica deposited cotton surface clearly shows the nano-roughening effect on cotton surface as shown in figure 2. Figure $2 \mathrm{a}$ is the cotton fibre surface before deposition which is smooth while figure $2 b$ is nanosilica deposited surface showing roughness due to particle deposition. This nano-roughness causes the super-hydrophobic cotton with low concentration of surface tension lowering agent.

\subsection{Contact angle measurement}

Contact angle was measured and photographs of water droplet on various samples were taken. In table 1, the first six samples were prepared through padding method while the last two were prepared by L-b-L method.

Very small amount of nanosilica $(0.16 \mathrm{wt} \%)$ padded with Arcofix and 2 wt $\%$ Nuva gave $133^{\circ}$ contact angle which is much greater than 2 wt $\%$ Nuva alone as can be observed from table 1. Roughness imparted by two-stage padding method with $0.16 \mathrm{wt} \%$ nanosilica and L-b-L self assembly approach is approximately same as the contact angles obtained with both methods are almost same. $0.5 \mathrm{wt} \%$ nanosilica or kaolin can impart $>150^{\circ}$ contact angle but a combination of nanosilica and nanoclay lowers down the contact angle as uniformity in roughness decreases using both of them in combination.

Figure 3 shows images of water droplets on untreated and treated cotton fabric surfaces. It has been clearly observed from the images that the nano roughening enhances the hydrophobic effect of $2 \mathrm{wt} \%$ Nuva treated samples.

From all the above points it can be concluded that the hydrophobic effect imparted by the low surface energy material increases with roughness and nanosilica performs best among the three systems chosen. It can be observed from table 1 that roughness significantly enhanced the hydrophobic nature of the cotton substrate. The combined effect of roughness and low surface energy material is more than that of low surface energy material used alone.

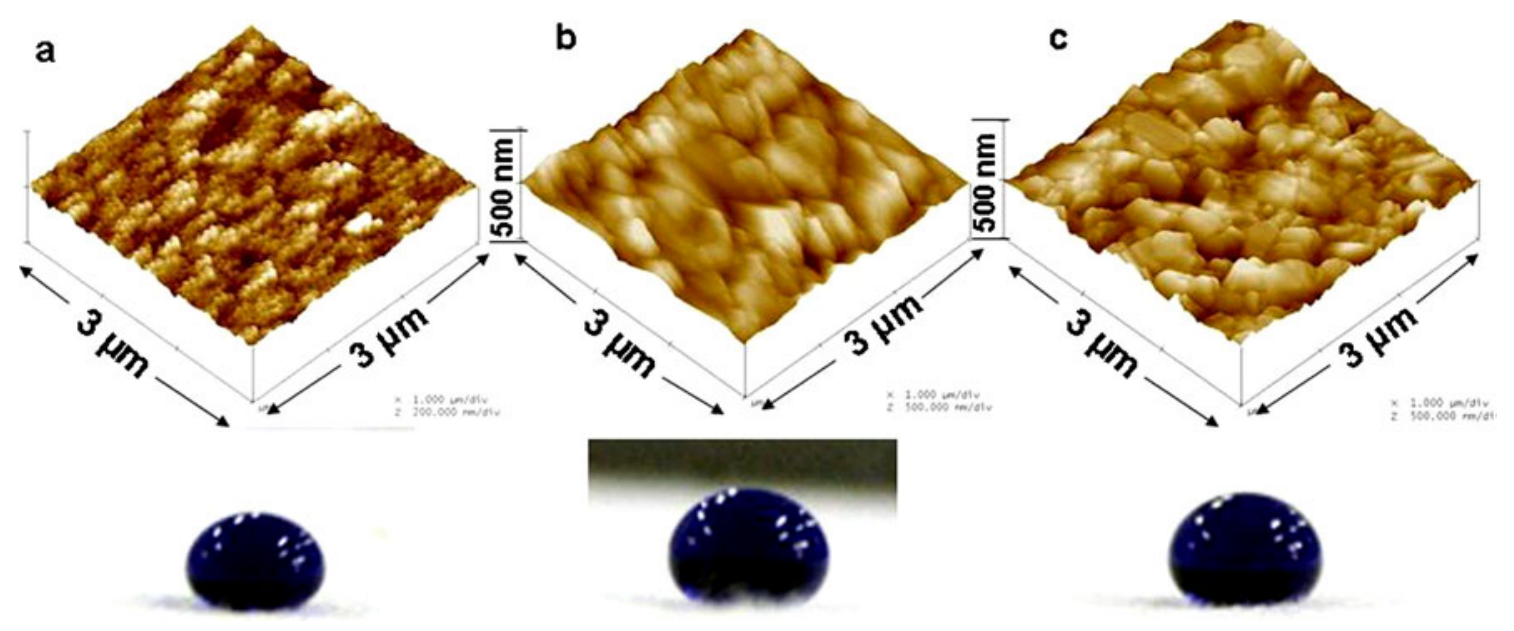

Figure 1. Nanoparticle roughened surface under AFM (top) and corresponding water drop image on nanoparticle deposited cotton surface (bottom): a. 1 wt $\%$ nanosilica deposited, b. 1 wt $\%$ nanoclay deposited and c. both nanosilica and nanoclay deposited ( $0.5 \mathrm{wt} \%$ each). 

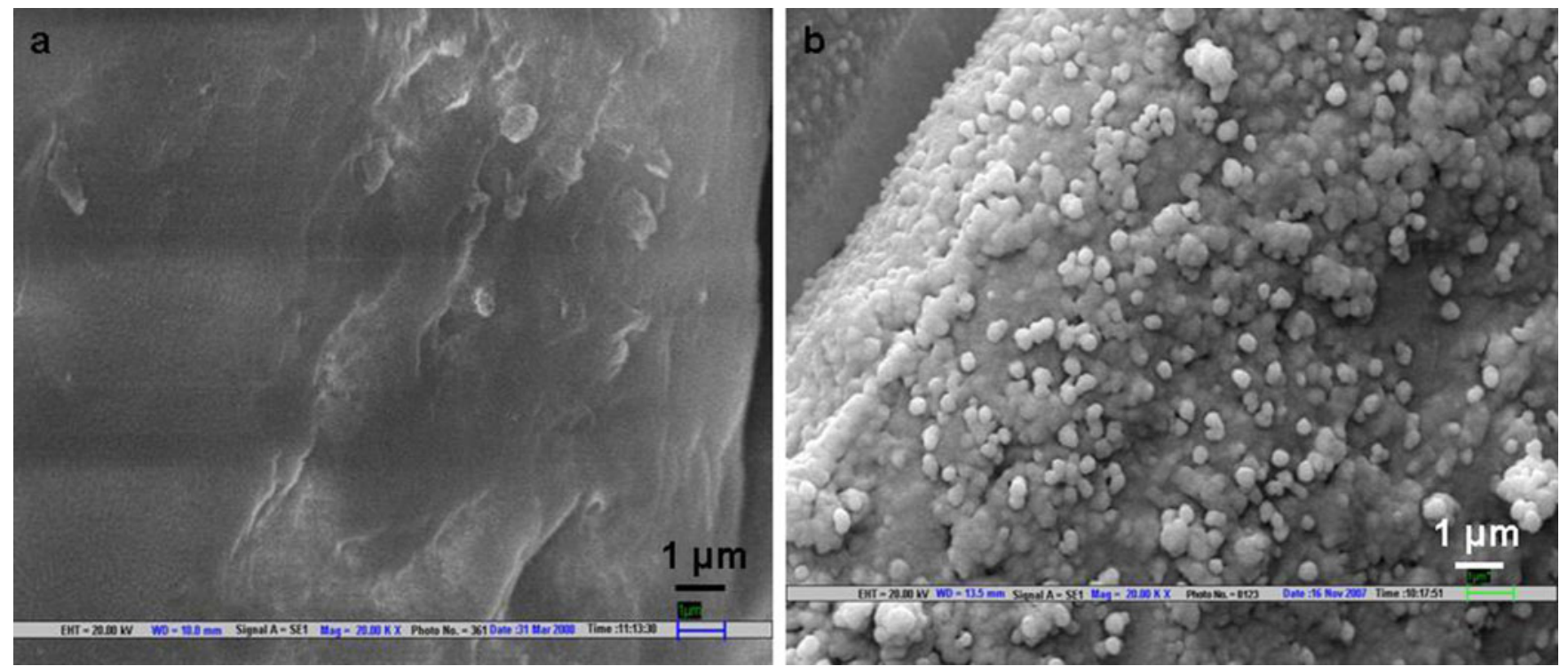

Figure 2. SEM images of a. cotton fibre surface and b. L-b-L nanosilica deposited cotton fibre surface after 5 bilayers.

Table 1. Contact angles for treated samples (average of 6 readings, both side of drops at three different places).

\begin{tabular}{|c|c|c|c|c|c|}
\hline $\begin{array}{l}\text { Sl. } \\
\text { no. }\end{array}$ & $\begin{array}{c}\text { Nanoparticle } \\
\text { used }\end{array}$ & $\begin{array}{l}\text { Technique } \\
\text { used }\end{array}$ & $\begin{array}{c}\text { Cross-linker } \\
\text { used }\end{array}$ & $\begin{array}{c}\text { Surface tension } \\
\text { lowering agent used }\end{array}$ & $\begin{array}{c}\text { Avg. contact } \\
\text { angle }\left(^{\circ}\right)\end{array}$ \\
\hline 1. & - & Pad-dry-cure & 3 wt $\%$ Arcofix & $4 \mathrm{wt} \%$ Nuva and $2 \mathrm{wt} \%$ Cerol & $143 \pm 1$ \\
\hline 2. & - & Pad-dry-cure & 3 wt $\%$ Arcofix & $2 \mathrm{wt} \%$ Nuva and $2 \mathrm{wt} \%$ Cerol & $115 \pm 1$ \\
\hline 3. & $0 \cdot 16 \mathrm{wt} \%$ nanosilica & Pad-dry-cure & 3 wt $\%$ Arcofix & $2 \mathrm{wt} \%$ Nuva and $2 \mathrm{wt} \%$ Cerol & $133 \pm 2$ \\
\hline 4. & $0.5 \mathrm{wt} \%$ nanosilica & Pad-dry-cure & 3 wt $\%$ Arcofix & $2 \mathrm{wt} \%$ Nuva and $2 \mathrm{wt} \%$ Cerol & $155 \pm 2$ \\
\hline 5. & $0.5 \mathrm{wt} \%$ kaolin & Pad-dry-cure & 3 wt $\%$ Arcofix & $2 \mathrm{wt} \%$ Nuva and $2 \mathrm{wt} \%$ Cerol & $153 \pm 3$ \\
\hline 6. & $0.5 \mathrm{wt} \%$ each of nanosilica and kaolin & Pad-dry-cure & 3 wt $\%$ Arcofix & $2 \mathrm{wt} \%$ Nuva and $2 \mathrm{wt} \%$ Cerol & $138 \pm 3$ \\
\hline 7. & $0.5 \mathrm{wt} \%$ nanosilica & 20 bilayers $\mathrm{L}-\mathrm{b}-\mathrm{L}$ & 3 wt $\%$ Arcofix & $2 \mathrm{wt} \%$ Nuva and $2 \mathrm{wt} \%$ Cerol & $122 \pm 2$ \\
\hline 8. & $0.5 \mathrm{wt} \%$ nanosilica & 40 bilayers $\mathrm{L}-\mathrm{b}-\mathrm{L}$ & 3 wt $\%$ Arcofix & $2 \mathrm{wt} \%$ Nuva and $2 \mathrm{wt} \%$ Cerol & $134 \pm 2$ \\
\hline
\end{tabular}

\subsection{Water repellency}

To evaluate the effect of roughness on hydrophobic nature of the surface, nanosilica based samples prepared by conventional finishing method were coated with $2 \mathrm{wt} \%$ Nuva HPU. This was done to see the combined effect of roughness and low surface energy material. AATCC test method 1932005 was done on samples to estimate the combined effect of roughness and low surface energy material.

It can be concluded from table 2 that $4 \mathrm{wt} \%$ Nuva gave the highest rating but lowering the concentration to $2 \mathrm{wt} \%$ had a deteriorating effect. The application of nanosilica also enhanced the effect of $2 \mathrm{wt} \%$ Nuva but it is not much without a cross linking agent. This happens because the particles are agglomerated on drying. However, formation of columnar structure with the help of silica, cross linking and surface tension lowering agent provided appropriate roughness to the surface. Rating achieved with combined effect of roughness and $2 \mathrm{wt} \%$ Nuva HPU is 5 which is very close to rating 6 of $4 \mathrm{wt} \%$ Nuva alone.

To see the effect of roughness on hydrophobic nature, the sample with best water repellency rating was tested for water repellency using Bundesmann rain shower test. First the sample holders were run blank then with different samples for same duration of time. Water penetrated through sample was noted down. Less the amount of water penetrated more is the water repellent effect.

Table 3 clearly shows that fabric treated with silica using finishing liquor gave hydrophobic effect to the cotton fabric because water penetrated is much less as compared to control fabric. This is due to columnar structure created by the combined effect of silica and other additives in the finishing liquor.

Table 4 describes the effect of number of bilayers of nanosilica in $\mathrm{L}-\mathrm{b}-\mathrm{L}$ technique on water repellency of cotton fabric. After nanosilica is deposited by $\mathrm{L}-\mathrm{b}-\mathrm{L}$ process with different number of bilayers, $2 \mathrm{wt} \%$ Nuva was applied on all samples before evaluating the effect of increased roughness with increasing number of bilayers.

In table 4, water repellency rating increased i.e. the hydrophobic effect increased from 5 to 40 bilayers. On comparing rating, it is clear that roughness is enhancing the hydrophobic effect imparted by low surface energy material. From 20 to 40 bilayers there is no effect on water repellency 


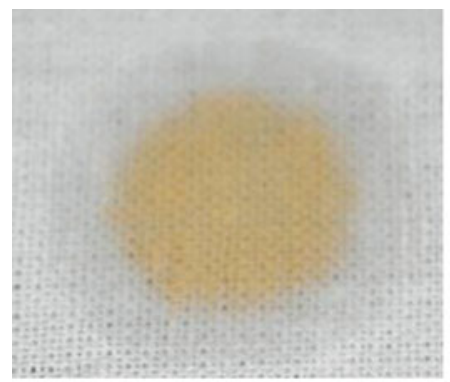

Untreated Sample

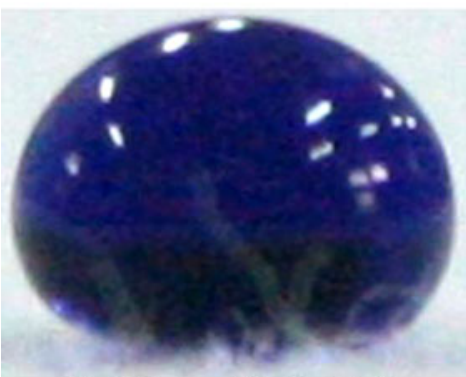

Padded with $0.16 \%$ nanosilica

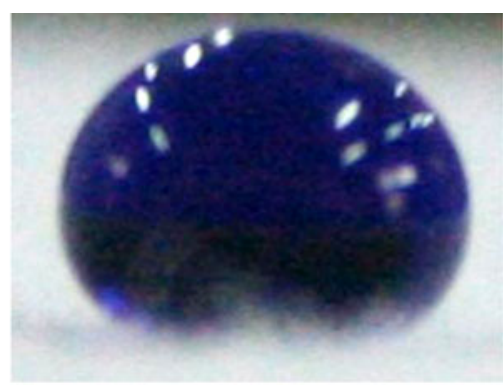

$4 \%$ Nuva

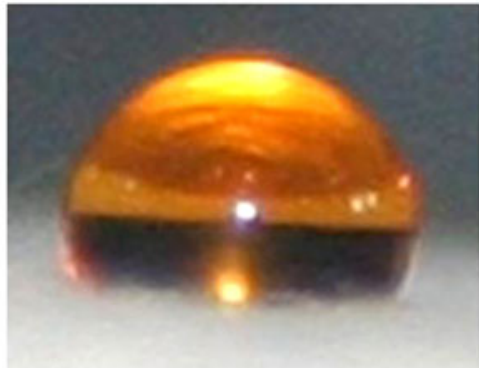

20 bilayers nanosilica + Padding with $2 \%$ Nuva

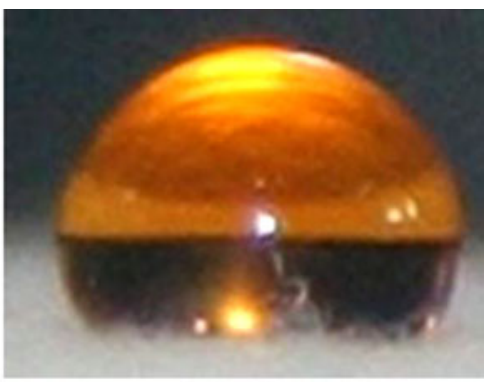

$2 \%$ Nuva

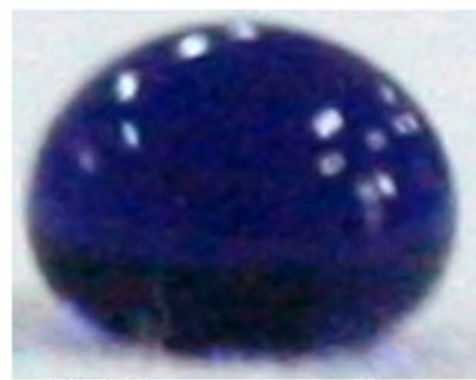

40 bilayers nanosilica + Padding with $2 \%$ Nuva

Figure 3. Photographs of water droplets on surface of various samples.

Table 2. Comparison of water repellency rating of nanosilica and nuva HPU treated samples.

\begin{tabular}{lc}
\hline Samples & $\begin{array}{c}\text { Water repellency } \\
\text { rating }\end{array}$ \\
\hline Untreated cotton fabric & 0 \\
Only $4 \mathrm{wt} \%$ Nuva HPU & 6 \\
Only $2 \mathrm{wt} \%$ Nuva HPU & 2 \\
$0 \cdot 26 \mathrm{wt} \%$ silica $+2 \mathrm{wt} \%$ Nuva HPU & 3 \\
$\quad$ (without cross linking agent) & \\
1 wt $\%$ silica +2 wt $\%$ Nuva HPU & 3 \\
$\quad$ (without cross linking agent) & \\
$0 \cdot 16$ wt $\%$ silica +3 wt $\%$ & 5 \\
Arcofix NDF +2 wt $\%$ Nuva HPU & \\
\hline
\end{tabular}

Table 3. Water penetration data using Bundesmann rain tester.

\begin{tabular}{lc}
\hline Sample & Water penetrated $(\mathrm{ml})$ \\
\hline Blank & 335 \\
Untreated fabric & 230 \\
$0 \cdot 16$ wt $\%$ silica $+3 \mathrm{wt} \%$ & 132 \\
Arcofix NDF $+2 \mathrm{wt} \%$ Nuva HPU &
\end{tabular}

rating, but contact angle was increased with number of bilayers (table 1) and the increase in hydrophobicity was also clearly visible (figure 3 ).
Table 4. Water repellency rating with increase in number of bilayers (in L-b-L technique).

\begin{tabular}{lc}
\hline Sample & Water repellency rating \\
\hline 2 wt $\%$ Nuva & 2 \\
5 bilayers $+2 \mathrm{wt} \%$ Nuva & 3 \\
10 bilayers $+2 \mathrm{wt} \%$ Nuva & 3 \\
15 bilayers $+2 \mathrm{wt} \%$ Nuva & 3 \\
20 bilayers $+2 \mathrm{wt} \%$ Nuva & 4 \\
30 bilayers $+2 \mathrm{wt} \%$ Nuva & 4 \\
40 bilayers $+2 \mathrm{wt} \%$ Nuva & 4 \\
\hline
\end{tabular}

Table 5. Air permeability of different samples.

\begin{tabular}{lc} 
Sample & $\left(\mathrm{cm}^{3} / \mathrm{cm}^{2} / \mathrm{s}\right)$ \\
\hline Cotton fabric (control) & 35.40 \\
25 bilayers of nanosilica deposited & 31.15 \\
40 bilayers of nanosilica deposited & 28.17 \\
15 bilayers of nanosilica $+2 \%$ Nuva & 33.97 \\
25 bilayers of nanosilica $+2 \%$ Nuva & 34.97 \\
40 bilayers of nanosilica $+2 \%$ Nuva & 35.13
\end{tabular}

\subsection{Air permeability}

To assess the effect of increasing number of bilayers of nanosilica deposited on the fabric using $\mathrm{L}-\mathrm{b}-\mathrm{L}$ process, air 
permeability of the fabrics has been examined and the results are given in table 5. It can be seen from table 5, that air permeability slightly decreased with increase in number of bilayers but when the commercial fluoro finish was applied over it, the values were again close to control sample. The application of fluoro chemical as such has no relation with increase in air permeability. But the padding and curing process during application of fluoro chemical reorganizes the loosely held nanosilica particles deposited on cotton surface. The result clearly indicates that the breathability of the fabric is not getting affected after $\mathrm{L}-\mathrm{b}-\mathrm{L}$ deposition and subsequent padding with surface tension lowering agent.

\section{Conclusions}

Nanosilica and nanoclay based nanoparticles have been successfully used to create super-hydrophobic cotton fabric with contact angle $>150^{\circ}$ having been achieved, wherein the water droplets just roll on the fabric surfaces, taking away the dust. Among the two methods of creating super-hydrophobic cotton, two-step dip coating method with $1 \mathrm{wt} \%$ nanosilica particle is best as the $\mathrm{L}-\mathrm{b}-\mathrm{L}$ process gives little advantage in terms of contact angle or durability and is also less industrially viable than the dip coating process. However, as far as the durability is concerned, the L-b-L deposited nanosilica with surface tension lowering agent and suitable cross linking agent holds promise as the fabric is repeatedly ultrasonicated during the deposition process to remove all the loosely held nanosilica. The hydrophobicity of such fabric samples is further supported by water repellency ratings, water permeation test or Bundesmann rain shower tester. The nanostructured coating on cotton fabric using nanosilica by both the padding as well as $\mathrm{L}-\mathrm{b}-\mathrm{L}$ process not only reduces the use of fluorocarbon or non-fluorocarbon based surface tension lowering agents but also enhances the hydrophobic behaviour significantly. The L-b-L technique further helps to retain the air permeability of the fabric, thus maintaining comfort characteristics of the fabric.

\section{References}

Bae G Y, Min B G, Jeong Y G, Lee S C, Jang J H and Koo G H 2009 J. Colloid Interf. Sci. 337170

Barthlott W and Ehler N 1977 Tropische und subtropische Pflanzenwelt. Akad. Wiss. Lit. Mainz 19110

Chang K C, Chen Y K and Chen H 2007 Surf. Coat. Technol. 201 9579

Garci M, de Rooij M, Winnubst L, van Zyl W E and Verweij H 2004 J. Appl. Polym. Sci. 921855

Joshi M and Bhattacharyya A 2011 Textile Progress 43(3) 155

Joshi M, Khanna R, Jha K and Shekar R 2011 J. Appl. Polym. Sci. 1192793

Kashiwagi T, Morgan A B, Antonucci J M, VanLandingham M R, Harris Jr. R H, Awad W H and Shields J R 2003 J. Appl. Polym. Sci. 892072

Song H J, Zhang Z Z and Men X H 2008 Composites: Part A 39188

Wong Y W H, Yuen C W M, Leung M Y S, Ku S K A and Lam H L I 2006 AUTEX Res. J. 61 (available at http://www.freewebs. com/jayaram-co/doc/Selected_Appz_of_Nanotechnology_in_ Textiles.pdf)

Xue C H, Jia S T, Zhang J and Tian L Q 2009 Thin Solid Films 517 4593

Yu M, Gu G, Meng W D and Qing F L 2007 Appl. Surf. Sci. 253 3669

Zhang X, Järn M, Peltonen J, Pore V, Vuorinen T, Levänen E and Mäntylä T 2008 J. Eur. Ceram. Soc. 282177 